\section{Commentary: Trial sequential analysis: An upgrade to the meta-analysis worth learning}

\author{
J. Hunter Mehaffey, MD, MSc, and \\ Robert B. Hawkins, MD, MSc
}

Drs Chan and Harky ${ }^{1}$ present a clinically relevant and timely review of trial sequential analysis (TSA) during a meta-analysis using a recent study published in the Journal. The authors performed a secondary analysis of the meta-analysis by Woldendorp and colleagues. ${ }^{2}$ The TSA methodology suggested that the existing evidence was sufficient to reach a conclusion about a $100 \%$ increase in risk of stroke in patients with subclinical valve thrombosis (SCVT) and a $20 \%$ reduction in SCVT incidence in patients taking oral anticoagulation compared with those taking single or dual antiplatelet therapy. However, contrary to the published results of the meta-analysis, the TSA methods suggest data are insufficient to confirm or rule out a $20 \%$ increase in SCVT risk in patients taking single versus dual antiplatelet therapy.

The authors are to be commended for proving a wellwritten review tailored to the cardiothoracic community. TSA originates from sequential interim analysis of clinical trials, a topic surgeons rarely encounter. Yet the adaptation for meta-analysis is becoming increasingly popular and the additional information provided means it will likely continue to grow in use. As the authors mention, there are important limitations of TSA, including underlying publication bias and heterogeneity in studies identified for meta-analysis. ${ }^{3}$ A meta-analysis is only as good as the studies that go into it, and the same applies to TSA. Additionally, the authors point out the important consideration that investigators arbitrarily set the thresholds for relative

\footnotetext{
From the Division of Thoracic and Cardiovascular Surgery, University of Virginia, Charlottesville, Va.

Disclosures: The authors reported no conflicts of interest.

The Journal policy requires editors and reviewers to disclose conflicts of interest and to decline handling or reviewing manuscripts for which they may have a conflict of interest. The editors and reviewers of this article have no conflicts of interest.

Received for publication July 6, 2020; revisions received July 6, 2020; accepted for publication July 7, 2020; available ahead of print July 12, 2020.

Address for reprints: Robert B. Hawkins, MD, MSc, Division of Thoracic and Cardiovascular Surgery, University of Virginia, PO Box 800679, Charlottesville, VA 22908 (E-mail: rbh6x@virginia.edu).

J Thorac Cardiovasc Surg 2021;162:174-5

$0022-5223 / \$ 36.00$

Copyright (c) 2020 by The American Association for Thoracic Surgery

https://doi.org/10.1016/j.jtcvs.2020.07.013
}

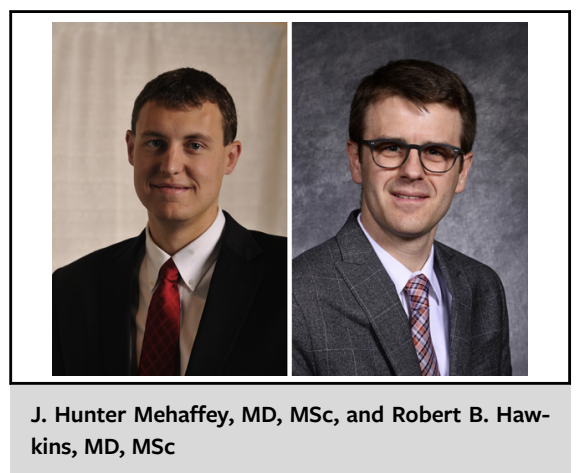

CENTRAL MESSAGE

TSA is an emerging and important addition to meta-analysis accounting for the growing body of evidence and should guide interpretation of results and decisions on future trials.

risk reduction, which drives the outcome of the analysis. These parameters should use clinical background and knowledge to guide selection; however, it is up to the reader to critically review these selections and assess their validity. ${ }^{4}$ Finally, as the authors demonstrate with the first outcome of $100 \%$ increase in risk of stroke with SCVT, the threshold for conclusive level of evidence was reached after only 3 studies, so more studies were superfluous. Therefore, this methodology can help guide decisions for future research and resource allocation. A recent article by Storz-Pfennig ${ }^{5}$ using TSA methodology demonstrated that 8 of the 13 trials studied were identified as potentially unnecessary research.

The TSA methodology is being applied more frequently in cardiothoracic studies and will continue to be an important adjunct to meta-analysis. This timely article by Chan and Harky ${ }^{1}$ provides a straightforward description of the methodology and a relevant example that is pertinent for practicing cardiothoracic surgeons.

\section{References}

1. Chan JH, Harky A. Trial sequential analysis in meta-analyses: a clinically oriented approach with real-world example. J Thorac Cardiovasc Surg. 2021;162:167-73.

2. Woldendorp K, Doyle MP, Black D, Ng M, Keech A, Grieve SM, et al. Subclinical valve thrombosis in transcatheter aortic valve implantation: a systematic review and meta-analysis. J Thorac Cardiovasc Surg. February 19, 2020 [Epub ahead of print].

3. Gartlehner G, Nussbaumer-Streit B, Wagner G, Patel S, Swinson-Evans T, Dobrescu A, et al. Increased risks for random errors are common in outcomes graded as high certainty of evidence. J Clin Epidemiol. 2019;106:50-9.
} 
4. Koster TM, Wetterslev J, Gluud C, Jakobsen JC, Kaufmann T, Eck RJ, et al. Apparently conclusive meta-analyses on interventions in critical care may be inconclusive-a meta-epidemiological study. J Clin Epidemiol. 2019;114:1-10.
5. Storz-Pfennig P. Potentially unnecessary and wasteful clinical trial research detected in cumulative meta-epidemiological and trial sequential analysis. J Clin Epidemiol. 2017;82:61-70.
See Article page 167

\section{Commentary: Not all meta-analyses can be trusted}

\author{
Stephanie K. Tom, MD, ${ }^{\mathrm{a}}$ \\ Emily Perdoncin, MD, FACC, ${ }^{\text {b }}$ and \\ Kendra J. Grubb, MD, MHA, FACC ${ }^{b}$
}

Systematic reviews and meta-analyses are widely viewed as the gold standard within the hierarchy of evidencebased medicine. These studies directly impact clinical guidelines and influence the way we practice medicine. However, clinicians may be unaware of the risk for introduction of random error, that is, type 1 error, when meta-analyses are small and underpowered, potentially inflating estimates of treatment effect. ${ }^{1}$ This risk may be further increased as evidence continues to accumulate and meta-analyses are updated over time, ultimately resulting in spurious data that can negatively affect how we deliver clinical care. ${ }^{2}$ Studies have shown that the risk of type 1 error could range from $10 \%$ to $30 \%$ of meta-analyses. ${ }^{2-4}$

The presented article by Chan and Harkey, ${ }^{5}$ "Trial Sequential Analysis in Meta-analyses: A Clinically Oriented Approach With Real World Example," provides a detailed introduction for the clinician to trial sequential analysis (TSA), an analytic method aimed at minimizing the chance of type 1 error in meta-analyses, by adjusting the test statistics accordingly as new trials or more data are added. ${ }^{5}$ The authors, using a post hoc TSA, performed

\footnotetext{
From the a Department of Surgery, Emory University, Atlanta, Ga; and ${ }^{\mathrm{b}}$ Structural Heart and Valve Center, Division of Cardiothoracic Surgery, Emory University, Atlanta, Ga.

Disclosures: The authors reported no conflicts of interest.

The Journal policy requires editors and reviewers to disclose conflicts of interest and to decline handling or reviewing manuscripts for which they may have a conflict of interest. The editors and reviewers of this article have no conflicts of interest.

Received for publication July 21, 2020; revisions received July 21, 2020; accepted for publication July 22, 2020; available ahead of print July 25, 2020.

Address for reprints: Kendra J. Grubb, MD, MHA, FACC, Structural Heart and Valve Center, Division of Cardiovascular Surgery, Emory University School of Medicine, 550 Peachtree St NE, 6th Floor, Atlanta, GA 30308 (E-mail: kjgrubb@emory.edu). J Thorac Cardiovasc Surg 2021;162:175-6 $0022-5223 / \$ 36.00$

Copyright (c) 2020 by The American Association for Thoracic Surgery https://doi.org/10.1016/j.jtcvs.2020.07.067
}

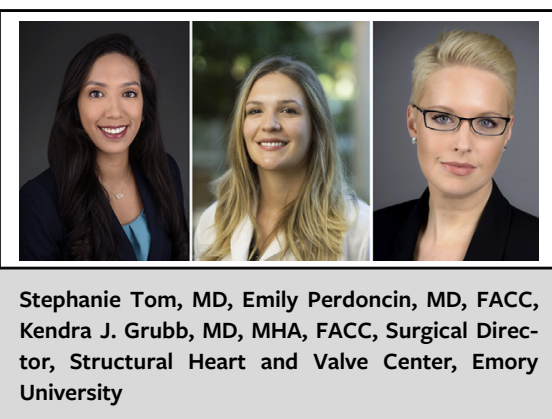

\section{CENTRAL MESSAGE}

TSA, a statistical tool for critical data analysis and confirmation, minimizes risk of type 1 error. TSA helps clinicians critically appraise data when considering applications to clinical practice.

an elegant reanalysis of data from the meta-analysis of Woldendorp and colleagues, ${ }^{6}$ which examined the associations among subclinical valve thrombosis (SCVT), stroke, and various antithrombotic strategies.

The reanalysis of the meta-analysis of Woldendorp and colleagues ${ }^{6}$ using TSA confirmed a $100 \%$ increase in the risk of stroke in patients with SCVT and a 20\% reduction in the incidence of SCVT in patients taking oral anticoagulants, as opposed to single antiplatelet therapy or dual antiplatelet therapy. Of note, with TSA, the observed $20 \%$ increase of SCVT in patients taking single antiplatelet therapy as opposed to dual antiplatelet therapy could not be considered conclusive because of underpowered data. As noted by the authors, the important limitations to TSA include susceptibility to bias and heterogeneity. In fact, the conclusion regarding the superiority of oral anticoagulants to antiplatelet therapies must be interpreted with caution, because significant heterogeneity was detected.

TSA appears to be a strong, although complex, statistical tool that allows for the critical analysis and confirmation of data with the goal of minimizing the risk of type 1 error. 